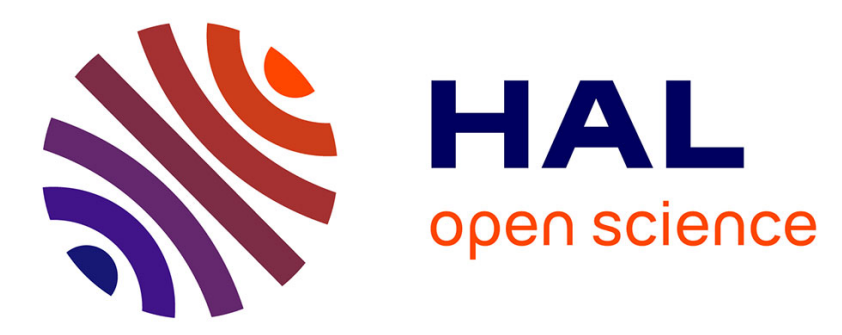

\title{
Optimal Scheduling of Multiproduct Pipeline System Using MILP Continuous Approach
}

Wassila Abdellaoui, Asma Berrichi, Djamel Bennacer, Fouad Maliki, Latéfa Ghomri

\section{- To cite this version:}

Wassila Abdellaoui, Asma Berrichi, Djamel Bennacer, Fouad Maliki, Latéfa Ghomri. Optimal Scheduling of Multiproduct Pipeline System Using MILP Continuous Approach. 6th IFIP International Conference on Computational Intelligence and Its Applications (CIIA), May 2018, Oran, Algeria. pp.411-420, 10.1007/978-3-319-89743-1_36 . hal-01913876

\section{HAL Id: hal-01913876 https://hal.inria.fr/hal-01913876}

Submitted on 6 Nov 2018

HAL is a multi-disciplinary open access archive for the deposit and dissemination of scientific research documents, whether they are published or not. The documents may come from teaching and research institutions in France or abroad, or from public or private research centers.
L'archive ouverte pluridisciplinaire HAL, est destinée au dépôt et à la diffusion de documents scientifiques de niveau recherche, publiés ou non, émanant des établissements d'enseignement et de recherche français ou étrangers, des laboratoires publics ou privés.

\section{(c)(1)}

Distributed under a Creative Commons Attribution| 4.0 International License 


\title{
Optimal scheduling of multiproduct pipeline system using MILP continuous approach
}

\author{
Abdellaoui Wassila $^{1 *}$, Berrichi Asma $^{1}$, Bennacer Djamel $^{2}$, Malik Fouad $^{1}$, \\ Ghomri Latefa ${ }^{1}$ \\ ${ }^{1}$ University Abou Bekr Blkaid, Dept. of Electrical Engineering Tlemcen, Algeria \\ ${ }^{2}$ University Abou Bekr Blkaid: Dept. of Mechanical Engineering Tlemcen, Algeria \\ 1*abdellaouiwgp@gmail.com
}

\begin{abstract}
To date, the multiproduct pipeline transportation mode has nationally and internationally considerably evolved thanks to his efficiently and effectively of transporting several products. In this paper, we focus our study on the scheduling of a multiproduct pipeline system that receives a number of petroleum products (fuels) from a single refinery source in order to be distributed to several storage and distribution centers (depots). Mixed Integer Linear Programming (MILP) continuous mathematical approach is presented to solve this problem. The sequence of injected products in the same pipeline should be carefully studied, in order to meet market demands and ensure storage autonomy of the marketable pure products in the fuels depots on the one hand and to minimize the number of interfaces; Birth zone of mixture between two products in contact and in sequential flow, which may hinder the continuous operation of the pipeline system, by the necessity of additional storage capacity for this last mixture, that is in no way marketable and requires special processing operations. This work is applied on a real case of a multiproduct pipeline that feeds the western and southwestern region of Algeria with fuels. The obtained results based on the MILP continuous approach give an optimal scheduling of the multiproduct transport system with a minimized number of interfaces.
\end{abstract}

Keywords: multiproduct pipeline; Scheduling; fuels; MILP continuous approach.

\section{Introduction}

Several million barrels of crude oil and oil derivatives such as diesel, gasoline, kerosene, jet fuel and liquid petroleum gases (LPG) are moved daily around the world in imports and exports. These products can be transported with different modes: roads, railroads, vessels, and pipelines among which the latter is the safest and least expensive way to distribute large quantities of energy products from source generally represented by the refineries to distribution terminals located in the different place $[1,2]$.

Among the best benefits of the pipeline, is its ability to operate 24 hours a day, regardless of weather conditions, with much lower operating costs than other inland transport modes [3]. 
Pipelines were first utilized by oil transportation companies of crude petroleum and its derivatives, where demand for these petroleum products is high. Oil industries are decided to expand pipeline utilization due to its low operating cost [4].

Products are injected in the pipeline one after the other in batch, in order to be transported to several distribution centers. Generally, we can distinguish two forms of the pipeline; the first one is straight-structured pipeline circulation of batches inside the pipeline, where the flow is established in one direction from source to centers. The second case is where the pipeline transfer products in two directions, called bidirectional pipelines, the last is called tree-structured pipeline because it takes the tree form and at each tree branch called "segment", a depot is located.

In this research, we are interested in the scheduling of multiproduct pipeline take the form of a straight-structured pipeline .Our goal is to find the optimal sequence of the new batches injection inside the pipeline; What allows to satisfy in wanted time daily requests of terminals and to minimize contaminant interface which results between the different batch of product and ensures an autonomy of stock of $20 \%$

\section{Literature Review}

Several works on the multiproduct pipeline systems problems have appeared over the last years. Many authors have presented different approaches for scheduling multiproduct pipeline systems in the literature: knowledge-based search techniques and mathematical programming approaches such as Mixed Integer Linear Programming (MILP) used by [5-9] formulations or Nonlinear Mixed Integer Programming (MINLP) formulations. The last can be divided into two approaches: discrete MILP approach and continuous MILP approach [10].

(Hane and Ratliff 1995), presented a discrete MILP model to transport several products from the refinery to diverse depots; this problem is divided into subproblems solved by branch and bound method [11].

(Rejowski and Pinto 2003), were studied a multiproduct system connected a unique refinery to several distribution centers that assure the demand of the local consumer markets. They proposed MILP model based on discrete time for scheduling this system .The model assumed in the beginning that le pipeline is divided into segments and each segment is divided into packs of equal volume, in the second they eliminated this assumption which says that the packs have the same volume [12].

The result of objective function ensures minimization of significant most operational costs, such inventory costs at the refinery and distribution centers, pumping costs and interface costs between adjacent products inside the pipeline, and moreover, the optimal sequence of injected products in the origin of pipeline and also the inventory levels at depot and refinery [1].

A year later, the same author adds special and non-intuitive practical constraints to the original model that can minimize volume between adjacent products (contaminant) inside the pipeline, and after, they included at the first MILP model a set of 
integer cuts that are based on the demand of depot and pipeline segment initial inventories [13].

(Cafaro and Cerdá 2004), propose to study the problem treated by [12] with a novel MILP continuous mathematical formulation, which does not require division of pipeline into packs and time discretization. So, it has continuous representation in time and volume. Something special for this presentation, that allows minimizing the number of binary variables and gives the best sequence of injected products into the pipeline with the best costs [14].

(Relvas et al. 2006), decided to integrate the distribution center operation with the multiproduct pipeline operation in their study. Their objective is to do both, the scheduling of the multi-product pipeline transport and the supply management in the depots. They have applied this model to a real case of a Portuguese oil distribution company[15]. (Cafaro and Cerdá 2008b), studied the problem of scheduling of multiproduct with different assumptions where clients demand was dynamic and they used a multi period moving horizon. They were giving good results appropriate to the real case with very short computational time [16].

(Relvas et al. 2006), developed a heuristic that can find the optimal sequence of pumped products into the pipeline, they use this heuristic for a short to medium term horizon. (MirHassani et al. 2011), presented an algorithm for the long-term planning of a simple multiproduct pipeline. The algorithm used a continuous MILP model for a short-term schedule to come to a long-term schedule. The objective function was minimizing the penalty costs of non-use of pipeline capacity, interface costs and cost of no satisfied customer demand[17].

(Rejowski and Pinto 2008), The authors present a new mixed-integer non-linear programming (MILP) for intermittent multiproduct pipeline scheduling which takes into account several constraints like different flow rates, pipeline works intermittently.. etc This representation gives a good result comparing with (Rejowski \& Pinto, 2004) which use a discrete representation of time [18].

Recently, the authors are interested in pipeline networks with multiple origins and destinations have been studied; Like what they did Cafaro DC, Cerda J (2016), Introduce a new tool for optimizing the short-term planning of petroleum product pipelines; Mixed-integer linear programming (MILP) model is expanded to treat pipeline networks with multiple sources, unidirectional flow and a single pipeline between every pair of the adjacent distribution center [19].

\section{Problem Statement}

In this paper we aim to study the activities scheduling in multiproduct pipeline system of a straight-structured unidirectional pipeline type, connecting a unique origin (refinery) to multiple distribution centers (in the case study we have two centers.

The experiment site is a $168-\mathrm{km}$ multiproduct pipeline linking a refinery in western Algeria to storage and fuel distribution centers. Fuels moved in batches (We note four pure fuel batches, P1, P2, P3 and P4) from the refinery tank farm through pumping 
station without any physical separation between adjacent products. An area of mixture was established between batches, where this last zone of the mixture progress until reaching the terminal at pipeline's end. The number of mixture depends on the number of initial products injected in the pipeline [20]. Figure 1 shows the physical structure of studied pipeline system.

The problem purpose is to determine sequence and volumes of new product batches to be pumped in the pipeline, in order to meet market demands and ensure products storage autonomy or the security stock in depots (fixed to $20 \%$ of overall storage capacity of each center) with number of interface between adjacent products $p$ and $p$ ' inside the pipeline minimized (Reduced).

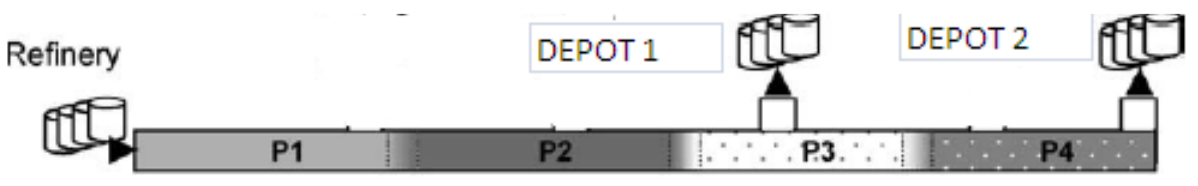

Fig.1.Single unidirectional multiproduct pipeline system

\section{a. 3.1 Model Assumptions}

(a) All products move in the pipeline without any physical separation between every two products in contact.

(b) The pipeline is always full, so if we think to receive a quantity of products from all the depots, it's necessary to inject the same amount at the origin of the pipeline.

(c) At any new pumping operation, only a unique product i.e. single batch is injected into the pipeline.

(d) Length of the planning horizon is fixe.

(e) Volume between adjacent products in pipeline (contaminant) was fixe.

(f) The scheduling model will meet the demand of products by the depots for daily sales to satisfy customer.

\section{Optimization Model}

\begin{tabular}{|ll|}
\hline \multicolumn{2}{|c|}{ Nomenclature } \\
Sets & Set of batch $\left(\mathrm{I}^{\text {old }} \cup\right.$ new $)$ \\
$\mathrm{I}^{\text {old }}$ & Set of batch inside pipeline \\
\hline
\end{tabular}




\begin{tabular}{|c|c|}
\hline $\mathrm{I}^{\text {new }}$ & Set of new batch that will be injected in pipeline \\
\hline $\mathrm{J}$ & Set of distribution center \\
\hline $\mathrm{P}$ & Set of Product \\
\hline \multicolumn{2}{|c|}{ Parameters } \\
\hline $\mathrm{L}_{\mathrm{i}}$ & Time of injection of batch i \\
\hline $\mathrm{S}_{\mathrm{i}}$ & Time starting pumping the batch $\mathrm{i}$ \\
\hline $\operatorname{mix}\left(p, p^{\prime}\right)$ & $\begin{array}{l}\text { Volume interface between the batch } \mathrm{i} \text { and batch } \mathrm{i}+1 \text { include le } \\
\text { product } \mathrm{p} \text { after } \mathrm{p} \text { ' }\end{array}$ \\
\hline \multicolumn{2}{|c|}{ Variables } \\
\hline $\mathrm{vm}_{\mathrm{h}, \mathrm{j}, \mathrm{i}}$ & $\begin{array}{l}\text { Volume batch } \mathrm{h} \text { delivered distribution center } \mathrm{j} \text { from the pipeline } \\
\text { during the injection of the batch } \mathrm{i}\end{array}$ \\
\hline$n v s_{p, j, i}$ & $\begin{array}{l}\text { Stock level of product } p \text { in the distribution center } j \text { at the end of the } \\
\text { batch i injection }\end{array}$ \\
\hline $\mathrm{vm}_{\mathrm{h}, \mathrm{j}, \mathrm{i}}$ & $\begin{array}{l}\text { Volume batch } \mathrm{h} \text { delivered distribution center } \mathrm{j} \text { from the pipeline } \\
\text { during the injection of the batch } \mathrm{i}\end{array}$ \\
\hline $\mathrm{INV}_{\mathrm{i}, \mathrm{p}, \mathrm{p}}$ & $\begin{array}{l}\text { Interface volume between batch } \mathrm{i} \text { and }(\mathrm{i}-1) \text { if they contain prod- } \\
\text { ucts } \mathrm{p} \text { and } \mathrm{p} \text { ? }\end{array}$ \\
\hline$y_{i, p}$ & $\begin{array}{l}\text { Binary variable denoting that product } p \text { is contained in batch } i \\
\text { whenevery } i, p=1 \text { Otherwise } y_{i, p}=0\end{array}$ \\
\hline
\end{tabular}

\subsection{Objective Function}

Problem objective Function is given in equation (1) consisted to minimize the interface volume between two adjacent products in the pipeline.

$$
\min \sum_{i \in I} \sum_{p \in P} \sum_{p^{\prime} \in P} I N V_{i, p, p^{\prime}}
$$

\subsection{Constraints}

\subsubsection{Product Allocation to Batch}

$\mathrm{y}_{\mathrm{i}, \mathrm{p}}$ is the binary variable, shows that product $p$ is contained in batch 1 it takes value $\mathrm{y}_{\mathrm{i}, \mathrm{p}}=1$, if else $\mathrm{y}_{\mathrm{i}, \mathrm{p}}=0$. And every batch can, at more, take one product so:

$$
\sum_{p \in P} y_{i, p} \leq 1 \quad \forall i \in I^{\text {new }}
$$

The new batch $i$ will be injected after batch $i-1$ so if batch $i-1$ take any product $\sum_{p \in P} y_{i-1, p}=0$ the batch $\mathrm{i}$ was not injected.

$$
\sum_{p \in P} y_{i, p} \leq \sum_{p \in P} y_{i-1, p} \forall i \in I^{\text {new }}
$$




\subsubsection{Batch sequencing}

The injection of a new batch $\mathbf{i} \in \mathbf{I}^{\text {new }}$ in the pipeline should start after the end of injected batch $\mathbf{i} \mathbf{- 1}$.

$S_{i} \geq S_{i-1}+L_{i-1} \forall i \in I^{\text {nouveaunew }}(i \geq 2)$

\subsubsection{Interface Volume Between Two Successive}

Inside the multiproduct pipeline, there is no physical separation between different products, so we record certain volume of intermixing between the two adjacent batches which is assumed a constant value and it is presented with $\operatorname{mix}\left(\mathbf{p}, \mathbf{p}^{\prime}\right)$. The continuous variable $\mathbf{I N V}_{\mathbf{i}, \mathbf{p}, \mathbf{p}^{\prime}}$ that presents interface volume between batches $\mathbf{i}$ and $\mathbf{i}+\mathbf{1}$ take the value of $\mathbf{m i x}\left(\mathbf{p}, \mathbf{p}^{\prime}\right)$, if product $\mathbf{p}$ was located in batch $\mathbf{i}$ and product $\mathbf{p}^{\prime}$ was located in batch $\mathrm{i}+1$.

$$
\sum_{i \in I} \sum_{p \in P} \sum_{p^{\prime} \in P} I N V_{i, p, p^{\prime}} \geq \operatorname{mix}\left(p, p^{\prime}\right) *\left(y_{i, \mathrm{p}}+y_{i+1, \mathrm{p}^{\prime}}-1\right)
$$

$\forall \mathrm{i} \in \mathrm{I}, \mathrm{i}<|\mathrm{I}|, \mathrm{p}, \mathrm{p}^{\prime} \in \mathrm{P}$

\subsubsection{Inventory in distribution center}

The inventory of products in distribution center $\mathrm{j}$ at the end of injection batch $\mathrm{i}$ was equal to the inventory product at the end of pumped batch $\mathrm{i}-1$ nvs $_{\mathrm{p}, \mathrm{j}, \mathrm{i}-1}$ by adding sum of product volume transferred to the distribution center during pumped batch $i$ $\left(\mathrm{vmp}_{\mathrm{h}, \mathrm{p}, \mathrm{j}, \mathrm{i}}\right.$ for depot 1 and $\mathrm{vsq}_{\mathrm{h}, \mathrm{p}, \mathrm{j}, \mathrm{i}}$ for depot 2 ) minus quantity delivery to clients.

$$
\begin{gathered}
n v s_{p, j, i}=v \operatorname{vint}_{p, j}+\sum_{h \in I, h \leq i} v m p_{h, p, j, i}-v_{p o m}, j, i \\
\forall p \in P, j \in J(j<|J|), i \in I^{\text {nouveau }}(i=\text { first new batch }) \\
n v s_{p, j, i}=n v s_{p, j, i-1}+\sum_{h \in I, h \leq i} v m p_{h, p, j, i}-v o m_{p, j, i} \\
\forall p \in P, j \in J(j<|J|), i \in I^{\text {new }}
\end{gathered}
$$

To ensure that the level inventory in distribution center was grater than or equal to the stock of security, we use the following constraint, where $\mathrm{ss}_{\mathrm{p}, \mathrm{j}}$ presents stock of security that is fixed at $20 \%$ of the overall stock capacities of each dept.

$$
n v s_{p, j, i} \geq s s_{p, j} \quad \forall p \in P, j \in J, i \in I^{\text {new }}
$$

\section{Result and Discussion}

5.1 Given : These data is harvest according to our real case study 
Table 1. Daily demand of depots

\begin{tabular}{lcc}
\hline product & Daily demand $\left[\boldsymbol{m}^{\mathbf{3}}\right]$ & \\
\cline { 2 - 3 } & Depot 1 & Depot 2 \\
\hline P1 & 1200 & 3000 \\
P2 & 400 & 800 \\
P3 & 80 & 150 \\
P4 & - & 150 \\
\hline
\end{tabular}

Table 2.Tanks storage capacities, products inventories and products security inventories

\begin{tabular}{lclllll}
\hline & \multicolumn{5}{l}{ Level Inventory $\left[\mathrm{m}^{3}\right]$} \\
\cline { 2 - 7 } product & Depot 1 & \multicolumn{5}{l}{ Depot 2} \\
\cline { 2 - 7 } & Capacity & $\begin{array}{l}\text { Initial inven- } \\
\text { tory }\end{array}$ & $\begin{array}{l}\text { security inven- } \\
\text { tory }\end{array}$ & Capacity & $\begin{array}{l}\text { Initial inven- } \\
\text { tory }\end{array}$ & $\begin{array}{l}\text { security inven- } \\
\text { tory }\end{array}$ \\
\cline { 2 - 7 } P1 & 6000 & 814 & 1200 & 22000 & 5572.4 & 4400 \\
P2 & 1700 & 809 & 340 & 9500 & 3394.6 & 1900 \\
P3 & 450 & 196 & 90 & 1000 & 996 & 200 \\
P4 & - & - & - & 5000 & 3284.7 & 1000 \\
\hline
\end{tabular}

Table 3.Interface volume and possible sequences between subsequent products inside the pipeline, $\mathrm{p}$ and $p^{\prime}$

\begin{tabular}{llccc}
\hline product & \multicolumn{4}{l}{ Volume Interface $\left[m^{3}\right]$} \\
\cline { 2 - 5 } & $P 1$ & $P 2$ & $P 3$ & $P 4$ \\
\hline$P 1$ & 28 & 28 & 30 & 0 \\
$P 2$ & 30 & & & \\
$P 3$ & 30 & & & \\
$P 4$ & & & & \\
\hline
\end{tabular}

Table 4.Initial batches volume inside pipeline at $\mathrm{t}=0$

\begin{tabular}{ll}
\hline \multicolumn{1}{c}{ Initial batchs inside pipeline } \\
& Volume $[\boldsymbol{m} \mathbf{3}]$ \\
\hline Batch01 (p2) & 520 \\
Batch01 (p1) & 9580 \\
\hline
\end{tabular}

\subsection{Analyses Result and Discussion}

The value of function objective was $320 \mathrm{~m}^{3}$ presented the total of interface mixture result between adjacent product inside the pipeline. They presented $2.30 \%$ of total 
volume, so we can say that the result was good more than can be satisfied the daily demand of client. The optimal sequence of the new batch injected inside the pipeline that can minimize the objective function was:

$$
p 3^{(1)}-p 1^{(2)}-p 2^{(3)}-p 1^{(4)}-p 3^{(5)}-p 1^{(6)}-p 2^{(7)}-p 1^{(8)}
$$

This sequence can minimize the number of an interface between adjacent product $p$ and p' and therefore minimize the objective function by satisfying the sales forecasts of centers and finally customer demands.

Table5. In Volume of a new batch injected inside the pipeline

\begin{tabular}{|c|c|c|c|c|}
\hline \multirow[t]{2}{*}{$\mathrm{N}^{\circ}$ of batch } & \multicolumn{2}{|c|}{ Volume of batch $\left[\mathrm{m}^{3}\right]$} & \multirow[b]{2}{*}{$p 3$} & \multirow[b]{2}{*}{$p 4$} \\
\hline & $p 1$ & $p 2$ & & \\
\hline Batch 1 & & & 386 & \\
\hline Batch 2 & 4776.5 & & & \\
\hline Batch 3 & & 8298.4 & & \\
\hline Batch 4 & 15000 & & & \\
\hline Batch 5 & & & 1029.1 & \\
\hline Batch 6 & 13710 & & & \\
\hline Batch 7 & & 10000 & & \\
\hline Batch 8 & & & & 2280 \\
\hline
\end{tabular}

Table5 shows the volumes of a new batch injected inside the pipeline satisfying the centers demands (depot 1 and 2) and ensure level tanks higher or equal than the stock of security.

Table6. Level tanks in the depot 1 at the end of injection of the new batch

\begin{tabular}{rcccccc}
\hline Batch & $\begin{array}{c}\text { Tank } \boldsymbol{p 1} \\
\text { Volume }\end{array}$ & \multicolumn{3}{c}{ Tank $\boldsymbol{p 2}$} & \multicolumn{3}{c}{ Tank $\boldsymbol{p 3}$} \\
Volume & $\%$ & $\begin{array}{c}\text { Volume } \\
{\left[\mathrm{m}^{3}\right]}\end{array}$ & $\%$ \\
Initial & 814 & 13.6 & 809 & 47.6 & 196 & 43.6 \\
Batch 1 & 1200 & 20 & 809 & 24,1 & 116 & 25.78 \\
Batch 2 & 2414.9 & 40.24 & 409 & 24.06 & 116 & 25.78 \\
Batch 3 & 4800 & 80 & 400 & 23.53 & 347.5 & 83.23 \\
Batch 4 & 2400 & 40 & 1480 & 87.06 & 187.55 & 41.67 \\
Batch 5 & 1200 & 20 & 1080 & 63.53 & 107.55 & 23.9 \\
Batch 6 & 4256 & 70.93 & 680 & 40 & 426.67 & 94.81 \\
Batch 7 & 3200 & 53.33 & 340 & 20 & 213.33 & 47.41 \\
Batch 8 & 1600 & 26.67 & 1260 & 74.12 & 106.67 & 23.71 \\
& & & & & & \\
\hline
\end{tabular}


Table 7 Level tanks in the depot 2 at the end of injection of the new batch

\begin{tabular}{lllcccccc}
\hline Batch & Tank $\boldsymbol{p 1}$ & \multicolumn{3}{c}{ Tank $\boldsymbol{p 2}$} & \multicolumn{3}{c}{ tank $\boldsymbol{p 3}$} & \multicolumn{3}{c}{ Tank $\boldsymbol{p 3}$} \\
& $\begin{array}{c}\text { Volume } \\
{\left[\mathrm{m}^{3}\right]}\end{array}$ & $\%$ & $\begin{array}{c}\text { Volume } \\
{\left[\mathrm{m}^{3}\right]}\end{array}$ & $\%$ & $\begin{array}{c}\text { Volume } \\
{\left[\mathrm{m}^{3}\right]}\end{array}$ & $\%$ & $\begin{array}{c}\text { Volume } \\
{\left[\mathrm{m}^{3}\right]}\end{array}$ & $\%$ \\
\hline Initial & 5572,4 & 25,3 & 3394,6 & 35,7 & 996 & 99,6 & 3284,7 & 65,7 \\
Batch 1 & 4400 & 20 & 2594.6 & 27.31 & 1000 & 90,6 & 3284.7 & 62,6 \\
Batch 2 & 4400 & 20 & 3100.6 & 32.64 & 905.55 & 90,6 & 3134.7 & 53,7 \\
Batch 3 & 5410.7 & 24.59 & 2300.6 & 24.22 & 755.55 & 90,6 & 2984.7 & 53,7 \\
Batch 4 & 6370.9 & 28.96 & 6700 & 70.53 & 500 & 45,6 & 2684.7 & 53,7 \\
Batch 5 & 4400 & 20 & 5900 & 62.11 & 350 & 100 & 2534.7 & 53,7 \\
Batch 6 & 10455 & 47.52 & 5100 & 53.68 & 200 & 55 & 2384,7 & 47,7 \\
Batch 7 & 11402 & 51.83 & 3800 & 40 & 400 & 55 & 2384.7 & 38,7 \\
Batch 8 & 5750.9 & 26.1 & 1900 & 20 & 200 & 40 & 1784,7 & 35,7 \\
\hline
\end{tabular}

In the table 6 and 7 we can see that tanks of all product at each depot (depot 1 and depot 2) at the end injection of the new batch; The level inventory was more than the stock of security so we assure that the probability of no satisfied the demands of clients will be decrease so always the demands of distribution centers was satisfied

\section{Conclusions}

Scheduling of a unidirectional multiproduct pipeline connecting a single refined to multiple distribution terminals is carried out with The MILP continuous approach. The MILP continuous can minimize the number of variable discussion compared to the MILP discrete and gives best results in the multiproduct pipeline problem scheduling case.

The MILP continuous was applied on the Algerian multiproduct pipeline scheduling. The pipeline in question links a refinery in western Algeria to two storage and fuel distribution centers. It has be seen that the use of MILP continuous approach gives the best result by taking into account the different operating conditions of the multiproduct pipeline which is served as experiment site.

The obtained results present an optimal solution that gives the sequence of new batches to be introduced in the pipeline. The flow configuration has reduced the number of interfaces between products $\mathrm{p}$ and $\mathrm{p}$ ' in contact and in a sequential flow, unlike to the current planning system of the company which is not based on recognized models.

Furthermore, we were able to quietly ensure autonomy storage that exceeds the required safety stock set at $20 \%$. 
Finally, our work based on MILP continuous approach can be considered as a decision support tool, to be called for use in the case of planning and scheduling of multiproduct pipeline use the MILP continuous approach for solve this type of problems.

\section{References}

1. Mostafaei, H., Alireza, GH.: A general modeling framework for the long-term scheduling of multiproduct pipelines with delivery constraints. Ind. Eng. Chem. Res 53 (17), 7029-7042 (2014).

2. LNCS Homepage, http:// www.aopl.org, last accessed 2001/12/12.

3. Cafaro, V., Cafaro, D., Mendez, C.A., Cerdá, J.: detailed scheduling of oil products pipelines with prallel batch input at intermediate source. Chemical Engineering Transactions 32, 13451350 (2013).

4. Hobson, GD., Pohl, W.: Modern Petroleum Technology. 5th edn. John Wiley \& Sons, England (1982).

5. Cafaro, V.G., Cafaro, D.C., Méndez, C.A., Cerdá, j.: Detailed Scheduling of Operations in Single-Source Refined Products Pipelines. nd. Eng. Chem. Res, 50 (10), 6240-6259(2011).

6. Cafaro, V.G., Cafaro, D.C., Méndez, C.A., Cerdá, j.:Detailed Scheduling of Single-Source Pipelines with Simultaneous Deliveries to Multiple Offtake Stations. Eng. Chem. Res, 51 (17), 6145-616 (2012).

7. Mostafaei, H., Castro, PM. Ghaffari-Hadigheh, A.: A Novel Monolithic MILP Framework for Lot-Sizing and Scheduling of Multiproduct Treelike Pipeline Networks. Eng. Chem. Res. 54 (37), 9202-9221 (2015)

8. Zaghian, A, Mostafaei, H. :An MILP model for scheduling the operation of a refined petroleum products distribution system Ali Zaghian. Operational Research - An International Journal(ORIJ) .16,513-542(2016).

9. Castro, PM., Mostafaei, H.: New Continuous-Time Scheduling Formulation for Multiproduct Pipelines.40,1381-1386(2017).

10. Cafaro, DC., Cerdá, J.: Efficient Tool for the Scheduling of Multiproduct Pipelines and Terminal Operations. Ind. Eng. Chem. Res 47, 9941-9956(2008).

11. Hane, C.A., Ratliff, H.D.: Sequencing inputs to multi-commodity pipelines. Annals of Operations Research 57,73-101(1995).

12. Rejowski, R., Pinto, J.M.: Scheduling of a multiproduct pipeline system. Comput Chem Eng 27,1229-1246 (2003).

13. Rejowski, R., Pinto, J.M: Scheduling of a multiproduct pipeline system. Comput Chem Eng 28, 1511-1528 (2004).

14. Cafaro, D.C., Cerda, J.: Optimal scheduling of multiproduct pipeline systems using a nondiscrete MILP formulation. Comput Chem Eng 28,2053-2068(2004).

15. Relvas, S., Matos, H.A., Barbosa-Povoa, A..P.F.D., Fialho, J., Pinheiro, A.S.:Pipeline scheduling and inventory management of a multiproduct distribution oil system.. Ind Eng Chem Res 45,7841-7855(2006).

16. Cafaro, D.C., Cerda, J.: Dynamic scheduling of multiproduct pipelines with multiple delivery due dates. Comput Chem Eng 32,728-753 (2008b).

17. MirHassani, S. A., Moradi, S.,Taghinezhad, N.:Algorithm for long-term scheduling of mui product pipelines. Eng. Chem. Res50 (24), 13899-13910 . (2011).

18. Rejowski, R., Pinto, J.M.: A novel continuous time representation for the scheduling of pipeline systems with pumping yield rate constraints. Comput Chem Eng 32,1042-1066(2008).

19. Cafaro, DC., Cerdá, J: Short-term operational planning of refined products pipelines. Optimization and Engineering 18, 241-268(2016). 
20. Bennacer, D., Saim R., Abboudi S., Benameur B.: Interface calculation method improves multiproduct transport. Oil \& Gas 114 (12), 74-80 (2016). 